\title{
Processes associated with ionic current rectification at a 2D-titanate nanosheet deposit on a microhole poly(ethylene terephthalate) substrate
}

\author{
Budi Riza Putra ${ }^{1,2} \cdot$ Christian Harito $^{3} \cdot$ Dmitry V. Bavykin $^{3} \cdot$ Frank C. Walsh $^{3} \cdot$ Wulan Tri Wahyuni $^{2} \cdot$ Jacob A. Boswell $^{1}$. \\ Adam M. Squires ${ }^{1} \cdot$ Julien M. F. Schmitt ${ }^{1} \cdot$ Marcelo Alves Da Silva $^{1} \cdot$ Karen J. Edler $^{1} \cdot$ Philip J. Fletcher $^{4} \cdot$ \\ Anne E. Gesell ${ }^{4}$. Frank Marken ${ }^{1}$ (D)
}

Received: 9 December 2018 / Revised: 13 January 2019 / Accepted: 16 January 2019 / Published online: 22 February 2019

(C) The Author(s) 2019

\begin{abstract}
Films of titanate nanosheets (approx. 1.8-nm layer thickness and 200-nm size) having a lamellar structure can form electrolytefilled semi-permeable channels containing tetrabutylammonium cations. By evaporation of a colloidal solution, persistent deposits are readily formed with approx. $10-\mu \mathrm{m}$ thickness on a $6-\mu \mathrm{m}$-thick poly(ethylene-terephthalate) (PET) substrate with a 20 - $\mu \mathrm{m}$ diameter microhole. When immersed in aqueous solution, the titanate nanosheets exhibit a p.z.c. of $-37 \mathrm{mV}$, consistent with the formation of a cation conducting (semi-permeable) deposit. With a sufficiently low ionic strength in the aqueous electrolyte, ionic current rectification is observed (cationic diode behaviour). Currents can be dissected into (i) electrolyte cation transport, (ii) electrolyte anion transport and (iii) water heterolysis causing additional proton transport. For all types of electrolyte cations, a water heterolysis mechanism is observed. For $\mathrm{Ca}^{2+}$ and $\mathrm{Mg}^{2+}$ ions, water heterolysis causes ion current blocking, presumably due to localised hydroxide-induced precipitation processes. Aqueous $\mathrm{NBu}_{4}{ }^{+}$is shown to 'invert' the diode effect (from cationic to anionic diode). Potential for applications in desalination and/or ion sensing are discussed.
\end{abstract}

Keywords Voltammetry $\cdot$ Ion valve $\cdot$ Ionic logic $\cdot$ Sensing $\cdot$ Nanostructure $\cdot$ Iontronics

\section{Introduction}

Ion binding and transport through microporous and mesoporous materials is of considerable importance in water purification and in membrane science $[1,2]$. Recent interest has arisen

\section{Frank Marken}

f.marken@bath.ac.uk

1 Department of Chemistry, University of Bath, Claverton Down, Bath BA2 7AY, UK

2 Department of Chemistry, Faculty of Mathematics and Natural Sciences, Bogor Agricultural University, Bogor, West Java, Indonesia

3 Energy Technology Research Group, Faculty of Engineering and the Environment, University of Southampton, Southampton SO17 1BJ, UK

4 Materials and Chemical Characterisation Facility (MCC), University of Bath, Claverton Down, Bath BA2 7AY, UK in particular in the porosity of new types of lamellar nanostructures (in particular graphene oxide [3, 4]), which are linked to ion transport [5] and water transport [6] phenomena, and the desire to exploit new types of lamellar 2D-materials more widely [7]. There are now ranges of novel materials available based, for example on 2D-nanosheets of modified carbons [8], phosphorous [9], oxides [10], chalcogenides [11] and mixed oxides such as $\mathrm{BiVO}_{4}$ [12] and MXenes [13]. 2Dtitanates have been of considerable interest and lamellar titanate deposits have been shown to be electrochemically and photo-electrochemically active depending on the $\mathrm{pH}$ and intercalated guest species [14]. In this report, we focus on titanate nanosheet materials that have been developed in pioneering work by Sasaki and coworkers $[15,16]$.

Titanate nanosheet materials are produced in two steps [17]; $\mathrm{TiO}_{2}$ reacts with caesium salts to give an intermediate solid lepidocrocite-type product, which is exfoliated into aqueous solution containing alkylammonium cations (here tetrabutylammonium, [18]) to give a stable colloidal solution 
of negatively charged titanate nanosheets. The surface charge of the colloid is associated with a point of zero charge (p.z.c.) at approximately $\mathrm{pH} 4$ [19]. The colloidal solutions contain single unit cell thick titanate layers, which are typically $200 \mathrm{~nm}$ in diameter [20]. The deposits of this colloid when dried up (without heating) give a lamellar gel with typically 1.7 to $1.8 \mathrm{~nm}$ unit cell spacing (based on the X-ray diffraction pattern, [21]). This is consistent with an approximately 1.2 - to 1.3-nm-thick titanate unit cell layer sandwiched between electrolyte layers of typically $0.5 \mathrm{~nm}$. At elevated temperature, these types of gels can collapse back to the anatase crystal form but, at room temperature, these lamellar nanostructures persist.

Applications of titanate nanosheets have been proposed as component in batteries [22], in heterogeneous catalysis [23], in photocatalysis [24] and as functional filler in polymer blends [25]. Recently, we have demonstrated that a film deposit of titanate nanosheet material on a glassy carbon electrode allows ferroceneboronic acid to be immobilised and binding of fructose within the nano-lamellar space to be detected [20]. Further study has shown that the titanate deposits behave more similar to organic media (and not to hydrophilic oxides) with the ability to bind hydrophobic organic molecules (e.g. anthraquinone) from cyclopentanone and to allow redox conversion of these immobilised inter-lamellar redox systems [26]. The ability to host hydrophobic guests has been attributed to the presence of tetrabutylammonium cations within the electrolyte layer.

In order to investigate ion transport through the lamellar titanate nanosheets, deposits of the titanate are studied here on a poly(ethylene-terephthalate) substrate (PET with 6- $\mu \mathrm{m}$ thickness) with a microhole (20- $\mu \mathrm{m}$ diameter). The experimental arrangement is very similar to that introduced by Girault et al. [27] for the study of liquid|liquid micro-interfaces. Recently, other types of ionomer systems (such as reconstituted cellulose [28], Nafion ${ }^{\mathrm{TM}}$ [29], the commercial ionomer Fumasep ${ }^{\mathrm{TM}}$ [30], graphene oxide [31] and a polymer of intrinsic microporosity [32]) have been investigated on this type of microhole substrate in order to reveal the mechanisms/ characteristics for ionic current rectification (or 'ionic diode' phenomena). The ionic diode or ionic current rectification effect requires a semi-permeable material. This type of effect allows cation transport (cationic diodes for cation conductors) and anion transport (anionic diodes for anion conductors) to be distinguished. New ideas for ionic current rectifier applications have been proposed, for example for water purification [33] or for ionic diode sensing [34].

The ionic diode effect caused in asymmetrically coated microholes can be explained (at least to a first approximation) based on a combination of ion conductivity and concentration polarisation phenomena [35]. Figure 1 provides a schematic summary of the key processes. With a symmetric ionomer deposit on both sides of the microhole, transport of ions from the left or from the right compartment remains the same and a simple resistance is observed rather than rectifier behaviour. However, with semi-permeable ionomer deposited only on one side (here, always on the side of the working electrode in a classic four-electrode measurement cell [36]), a distinct change in current occurs with an 'open' potential domain (due to accumulation of electrolyte in the microhole region; current flows) and a 'closed' potential domain (due to depletion of electrolyte in the microhole region; current is blocked). This is illustrated in Fig. 1 for the case of a cationic diode.

Ionic diode phenomena are associated with processes that occur at different length scales due to potential dependent compositional changes. There are different types of mechanisms, for example based on double-layer changes within nanopores, based on diffusion-migration layer compositional changes and due to interfacial precipitation or blocking. The diffusionmigration layer-based processes in microhole diodes (as described in Fig. 1) can be contrasted with processes reported in work on nanochannel diodes [37], nano-cones [38] and on electrolytic microfluidic/nanofluidic channel diodes [39, 40]. Other types of ionic diodes have been proposed based on gelgel interfaces [41]. Ionic circuits have been proposed based on polymer gels $[42,43]$. Ionic diode switching effects have been demonstrated also due to interfacial precipitation [44] and due to $\mathrm{pH}$ gradients [45]. The term 'iontronics' has been coined by Chun and Chung [46] to emphasise the excitement associated with developments functionality, such as that in ionic amplifiers [47], transistors [48] or flip-flops [36]. More fundamentally, ionic rectifiers under $\mathrm{AC}$-excitation can be considered as 'ion pumps'. A device based on coupling cationic diodes and anionic diodes has been proposed for desalination applications [33]. Selectivity in ionic diode behaviour is desirable in order to broaden the possible range of applications. In particular, selectivity for higher valent cations such as $\mathrm{Mg}^{2+}$ and $\mathrm{Ca}^{2+}$ could be very useful for water treatment applications.

In this report, ion transport in the inter-lamellar space of titanate nanosheets is investigated. The semi-permeable nature of titanate nanosheet deposits (immersed in electrolyte with not too high ionic strength) allows cation transport and therefore causes cationic diode effects. This is studied here for a wider range of electrolytes and conditions. Inversion to anionic diode behaviour is observed in the presence of tetrabutylammonium cations.

\section{Experimental}

\section{Chemical reagents}

Titanate nanosheet material was synthesised as described previously by Sasaki et al. [21] and by Harito et al. [49, 50]. Hydrochloric acid, sodium chloride, potassium chloride, lithium chloride, ammonium chloride, tetrabutylammonium chloride, magnesium chloride, calcium chloride, sodium 


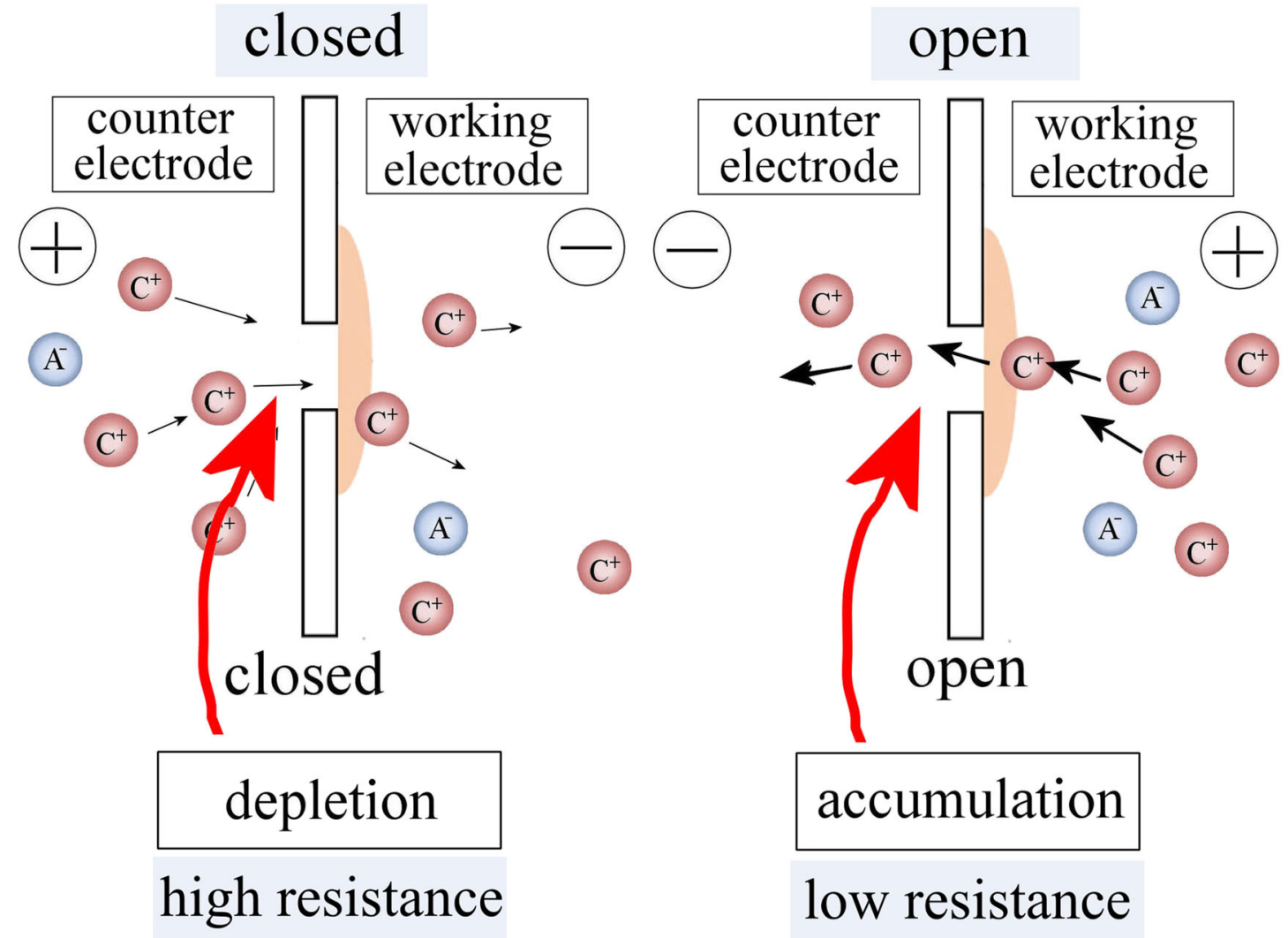

Fig. 1 Schematic depiction of the case of a semi-permeable cation conductor causing a 'cationic diode' effect. In the closed state, the flow of cations is limited by electrolyte depletion within the cylindrical section

hydroxide, sodium nitrate, sodium perchlorate and sodium sulphate were obtained in analytical grade from SigmaAldrich or Fischer Scientific and used without further purification. Phosphate buffer saline (PBS) was prepared with $\mathrm{NaH}_{2} \mathrm{PO}_{4}, \mathrm{Na}_{2} \mathrm{HPO}_{4}$ and $\mathrm{NaCl}$ and adjusted to $\mathrm{pH} 7$. Solutions were prepared under ambient condition in volumetric flasks with ultrapure water with resistivity of $18.2 \mathrm{M} \Omega \mathrm{cm}$ (at $22{ }^{\circ} \mathrm{C}$ ) from an ELGA Purelab Classic System.

\section{Instrumentation}

Electrochemical data (voltammetry and chronoamperometry) were recorded at $T=20 \pm 2{ }^{\circ} \mathrm{C}$ on a potentiostat system (Ivium Compactstat, The Netherlands). A classic four-electrode membrane electrochemical cell was used. The membrane separates two tubular half-cells (15-mm diameter, see Fig. 2a), one with Pt wire working and saturated calomel (SCE) sense electrode and the other with SCE reference electrode and Pt wire counter electrode. In electrochemical measurements, the working electrode was always located on the side of titanate nanosheet films. Fluorescence imaging was performed on a Carl Zeiss Confocal Scanning Microscope. For fluorescence analysis, rhodamine $\mathrm{B}$ was mixed with titanate nanosheet of the PET film. In the open state, electrolyte accumulation within the cylindrical section occurs due to oversupply of cations through the semipermeable cation conductor

colloidal solution, which was then applied to the PET films (see below).

\section{Procedures}

The zeta potential for the colloidal titanate solution was measured on a Zetasizer Nano ZS (Malvern Instruments Ltd., Malvern, UK) confirmed an average of $-32.5 \mathrm{mV}$ and an average size of $216 \mathrm{~nm}$ [26]. In order to form films of titanate nanosheets on PET substrates $(20-\mu \mathrm{m}$ diameter hole in $6-\mu \mathrm{m}$ thick PET from Laser Micromaching Ltd., Birmingham, UK), $10 \mu \mathrm{L}$ aqueous titanate nanosheet colloidal solution $\left(2.56 \mathrm{~g} \mathrm{~L}^{-1}\right)$ was applied to a PET film on a glass substrate (the glass was pre-coated with a thin layer of $1 \%$ agarose gel by solution casting to stop titanate nanosheet material penetrating through the PET microhole). A volume of $10 \mu \mathrm{L}$ titanate nanosheet colloidal solution was applied to the surface over PET to give a $1-\mathrm{cm}^{2}$ film coating, which after drying produced a thin uniform coating. For the formation of symmetric deposits on both sides of the PET film, the deposition was repeated on the back side of the PET. In order to image the $\mathrm{TiO}_{2}$ films, stacked fluorescence images were obtained for a symmetric (double-sided) and for the asymmetric (one-sided) deposits. 
(a)

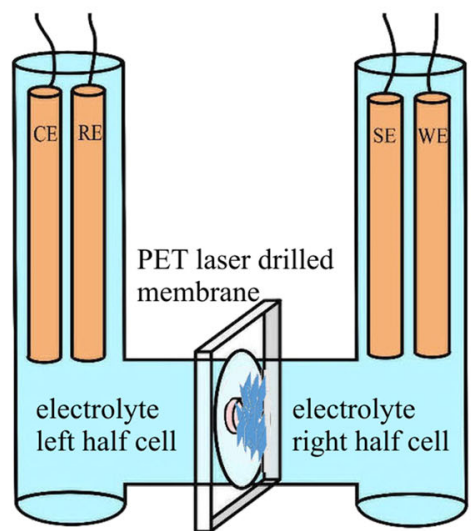

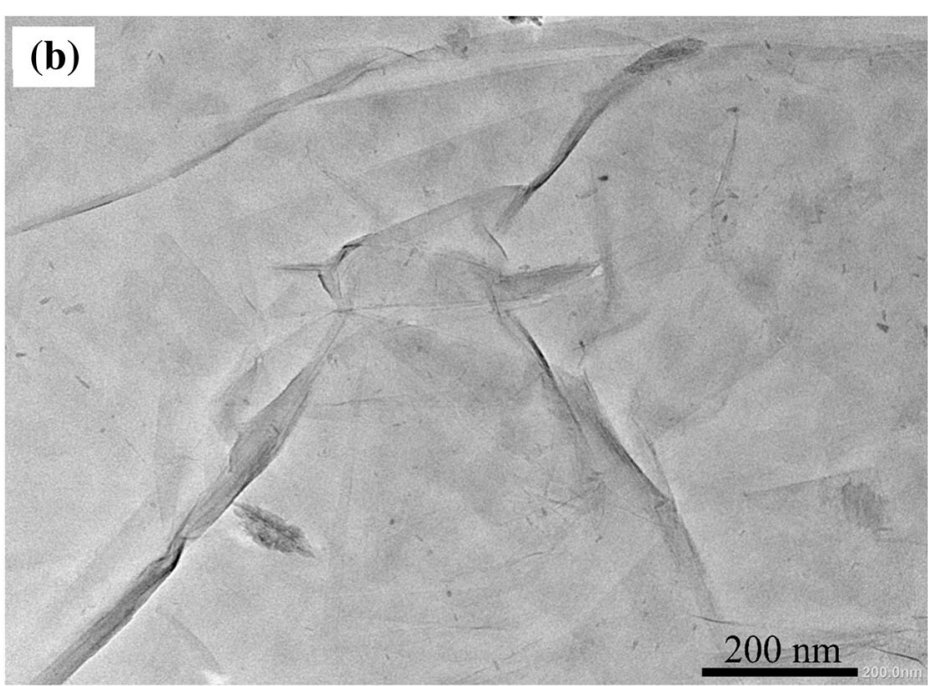

2D-nanooxide film deposit
Fig. 2 a Schematic description of the experiment with four-electrode control (WE, working electrode; SE, sense electrode; CE, counter electrode; RE, reference electrode) of the applied potential and $\mathrm{TiO}_{2}$

\section{Titanate nanosheet film characterisation}

Fluorescence microscopy with a rhodamine B stain reveals the presence of a uniform $\sim 5$ - to $10-\mu \mathrm{m}$-thick film of titanate nanosheets coated over a $20-\mu \mathrm{m}$ diameter microhole in a nanosheet deposit on the side of the working electrode. b A typical TEM image of the titanate nanosheet material is shown

PET substrate. Figure 3 shows a multi-stack fluorescence microscopy image as top view (with the focus on the PET layer) and as side view. For the symmetric diode (Fig. 3a), it can be seen that the $20-\mu \mathrm{m}$ microhole was partially filled with titanate nanosheet material. It can be clearly observed that there

\section{(a) symmetric}

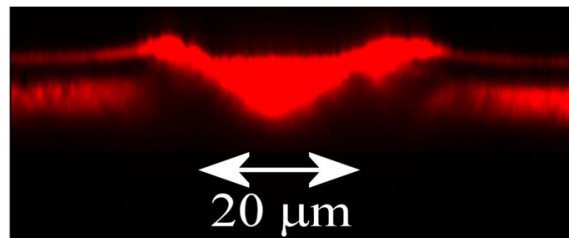

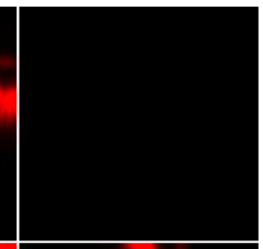

(b) asymmetric
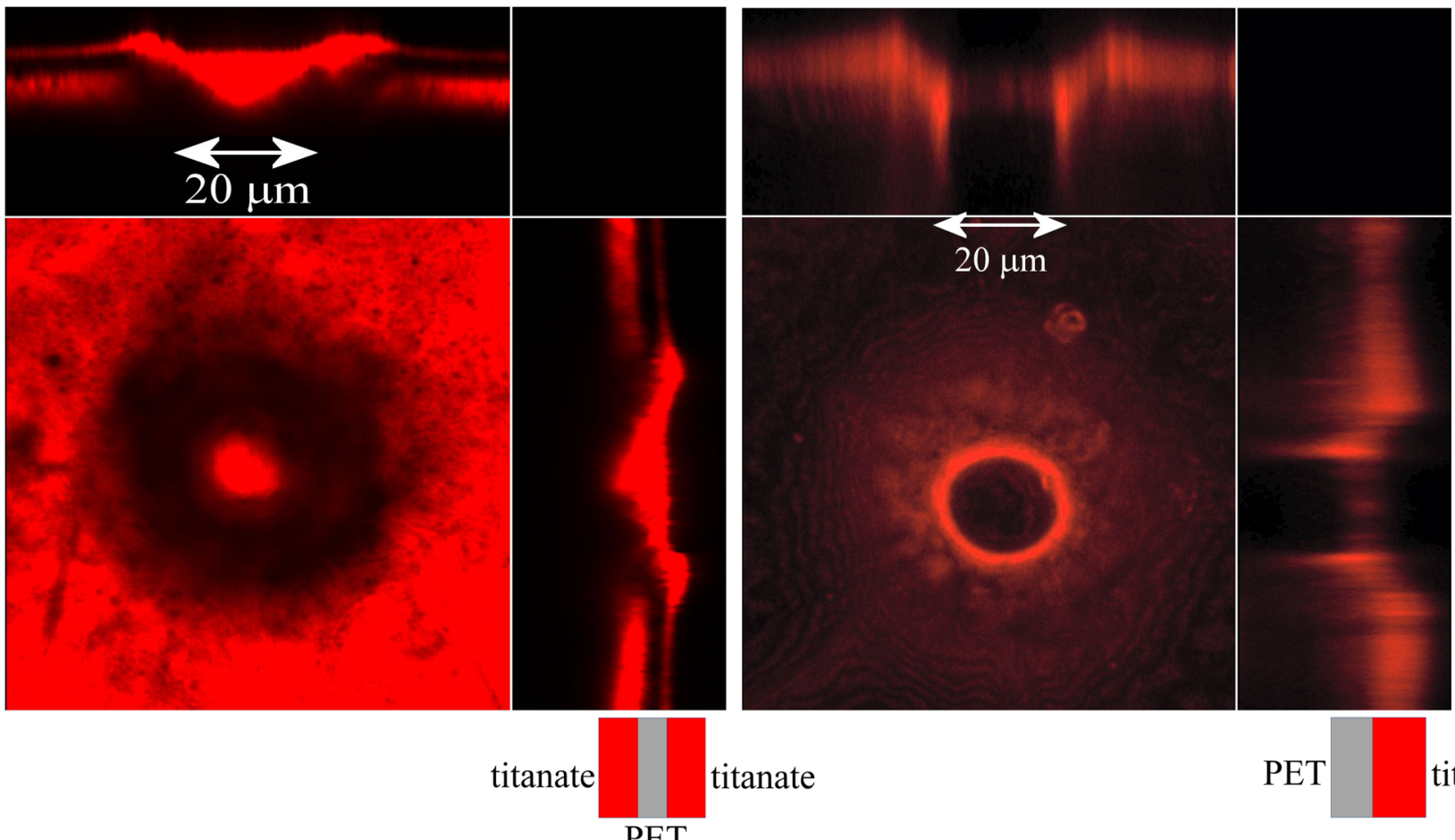

PET

titanate

Fig. 3 Fluorescence microscopy image stacks based on rhodamine $\mathrm{B}$ embedded into $\mathrm{TiO}_{2}$ nanosheet deposits a symmetric (applied from both sides) and b asymmetric (applied form only one side) to the PET substrate with $20-\mu \mathrm{m}$ diameter microhole 
are two layers of titanate nanosheets on opposite sides of the PET. However, for the asymmetric diode (Fig. 3b), the layer of titanate nanosheet material is seen on one side (ca. 5-10 $\mu \mathrm{m}$ thick). The extent of the deposit is not clearly resolved due to light reflection effects.

\section{Results and discussion}

\section{Ion transport through lamellar titanate nanosheet deposits: $\mathrm{Na}^{+}$transport}

Figure 4 a shows typical cyclic voltammetry data over a potential range of +4 to $-4 \mathrm{~V}$ applied to the nanosheet coated or uncoated PET membrane immersed in $10 \mathrm{mM} \mathrm{NaCl}$ on both sides. Three cases are shown: (i) a PET film with an empty 20- $\mu \mathrm{m}$ diameter hole, (ii) a PET film with titanate nanosheets deposited symmetrically on both sides and (iii) a PET film with titanate nanosheets deposited asymmetrically only on one side. For the empty microhole, the currents are dominated by the specific resistivity (giving a constant resistance) of the aqueous $\mathrm{NaCl}$ electrolyte solution filling the microhole [51]. With titanate nanosheets applied symmetrically on both sides, the current decreases for both negative and positive applied potentials due to the titanate restricting the flow of ions. For the asymmetric case, current rectification behaviour is observed with a higher current generated at positive applied potentials and a lower current generated at negative applied potentials. Figure 1 illustrates the corresponding cases of an open cationic diode (positive applied potential) and a closed cationic diode (negative applied potential) for the case of negatively charged titanate nanosheet material. Next, rectification phenomena are investigated with different concentrations of aqueous $\mathrm{NaCl}$ electrolyte solution.

Figure $4 \mathrm{~b}$ shows cyclic voltammetry data for asymmetrically deposited titanate nanosheets. Rectified currents flow with positive applied potentials and therefore cation conduction must be possible through the titanate deposit. With the increasing concentration of $\mathrm{NaCl}$ from 1 to $1000 \mathrm{mM}$, a welldefined steady-state voltammetric response is observed. For experiments at lower $\mathrm{NaCl}$ concentration, the current in the negative potential range is lower compared to the current in the positive potential range. This is consistent with cationic diode behaviour as seen in cases such as Nafion ${ }^{\mathrm{TM}}$ [29] and Fumasep ${ }^{\mathrm{TM}} \mathrm{FKS}-30$ ionomer [30]. The effect of $\mathrm{NaCl}$ electrolyte concentration on the currents and on the switching time for the cationic diode is shown more clearly in chronoamperometry data in Fig. 4 c. From these data, the rectification ratio can be calculated (obtained by dividing the absolute currents at $+1 \mathrm{~V}$ and at $-1 \mathrm{~V}$; see inset in Fig. $4 \mathrm{~b}$ ). An increase in $\mathrm{NaCl}$ concentration causes an increase in both the current in the open state and the current in the closed state. An optimum in rectification effect is observed in the range
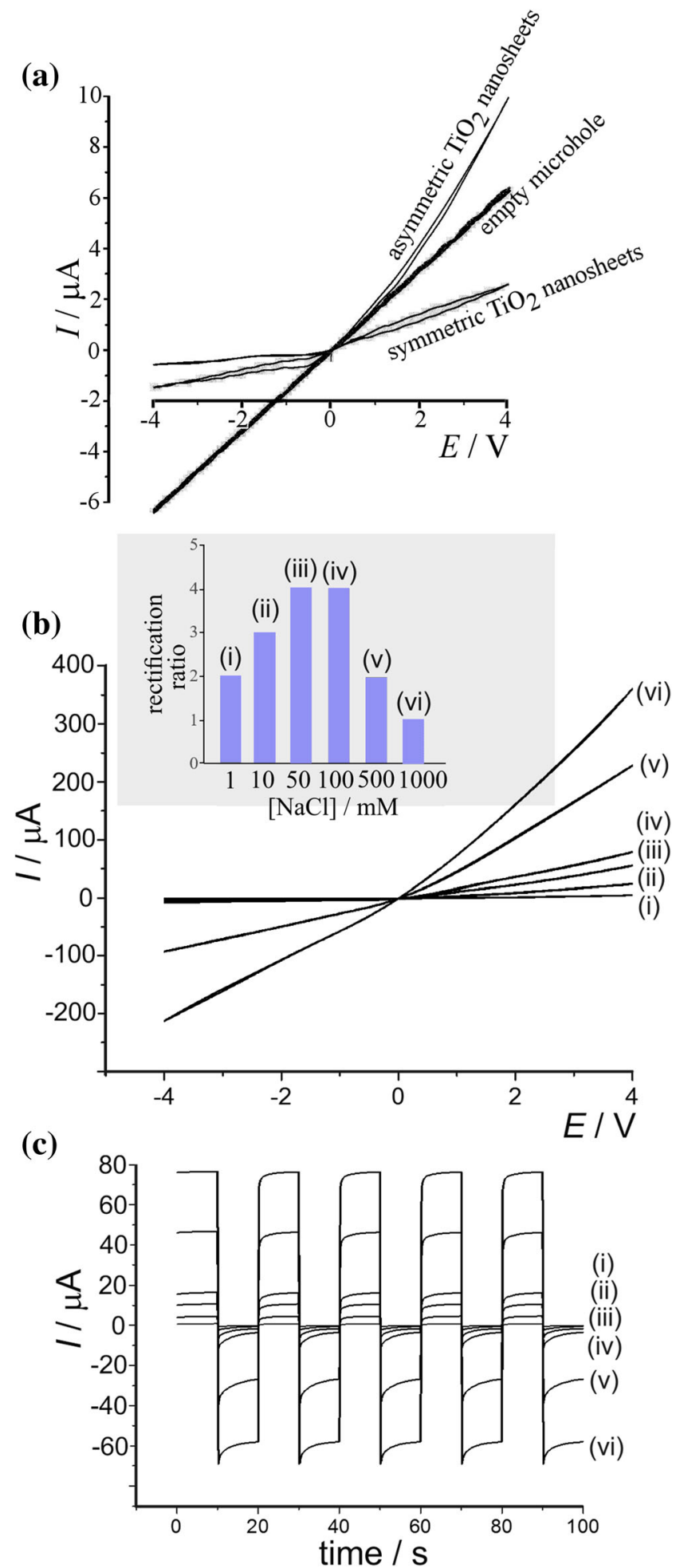

Fig. 4 a Cyclic voltammograms (scan rate $50 \mathrm{mV} \mathrm{s}^{-1}$ ) for (i) an empty microhole, (ii) a symmetric titanate deposit and (iii) an asymmetric titanate deposit (microhole diameter $20 \mu \mathrm{m}$ ) immersed in $10 \mathrm{mM} \mathrm{NaCl}$. b Data for asymmetrically deposited titanate nanosheets showing cyclic voltammograms (scan rate $25 \mathrm{mV} \mathrm{s}^{-1}$ ) in aqueous $\mathrm{NaCl}$ and $\mathbf{c}$ chronoamperometry responses (stepping from +1 to $-1 \mathrm{~V}$ ) immersed in aqueous $\mathrm{NaCl}$ with a concentration of (i) 1 , (ii) 10 , (iii) 50 , (iv) 100 , (v) 500 , (vi) $1000 \mathrm{mM} \mathrm{NaCl}$ on both sides. Inset: rectification ratios from chronoamperometry data at $\pm 1 \mathrm{~V}$ 
from 50 to $100 \mathrm{mM} \mathrm{NaCl}$ solution. The decrease in rectification ratio when going to higher ionic strength can be explained due to loss of semi-permeability and onset of anion transport through the titanate nanosheet film.

\section{Ion transport through lamellar titanate nanosheet deposits: electrolyte cations versus anions}

Next, the effects of electrolyte cations and anions on titanate nanosheet transport are investigated in order to better understand cationic diode processes. Figures $5 \mathrm{a}-\mathrm{b}$ show a summary of data from cyclic voltammogram, chronoamperometry and rectification ratio bar plots for aqueous $10 \mathrm{mM} \mathrm{HCl}, \mathrm{NaCl}, \mathrm{KCl}, \mathrm{LiCl}$, $\mathrm{NH}_{4} \mathrm{Cl}, \mathrm{MgCl}_{2}$ and $\mathrm{CaCl}_{2}$. All salt systems show some conductivity, but there are distinct changes depending on the type of cation. Currents for the open diode are considerably higher in the presence of monovalent cations such as $\mathrm{H}^{+}, \mathrm{Li}^{+}, \mathrm{Na}^{+}, \mathrm{K}^{+}$and $\mathrm{NH}_{4}{ }^{+}$compared to those for divalent cations such as $\mathrm{Mg}^{2+}$ and $\mathrm{Ca}^{2+}$. This could be consistent with a higher mobility for monovalent cations relative to divalent cations. However, the ability of cations to bind/transfer is affected by water heterolysis and will be investigated in more detail below. Among the monovalent cations, protons gave the highest currents and rectification ratio (Fig. 5a-b).

Next, the effects of electrolyte anions are investigated. Figures $5 \mathrm{c}-\mathrm{d}$ show a summary of data from cyclic voltammogram, chronoamperometry and a rectification ratio bar plot for aqueous $10 \mathrm{mM} \mathrm{NaOH}, \mathrm{NaNO}_{3}, \mathrm{NaCl}, \mathrm{NaClO}_{4}, \mathrm{Na}_{2} \mathrm{SO}_{4}$ and PBS pH 7. For all types of anions, similar levels of rectification are observed. Currents for the open diode (in the (a)

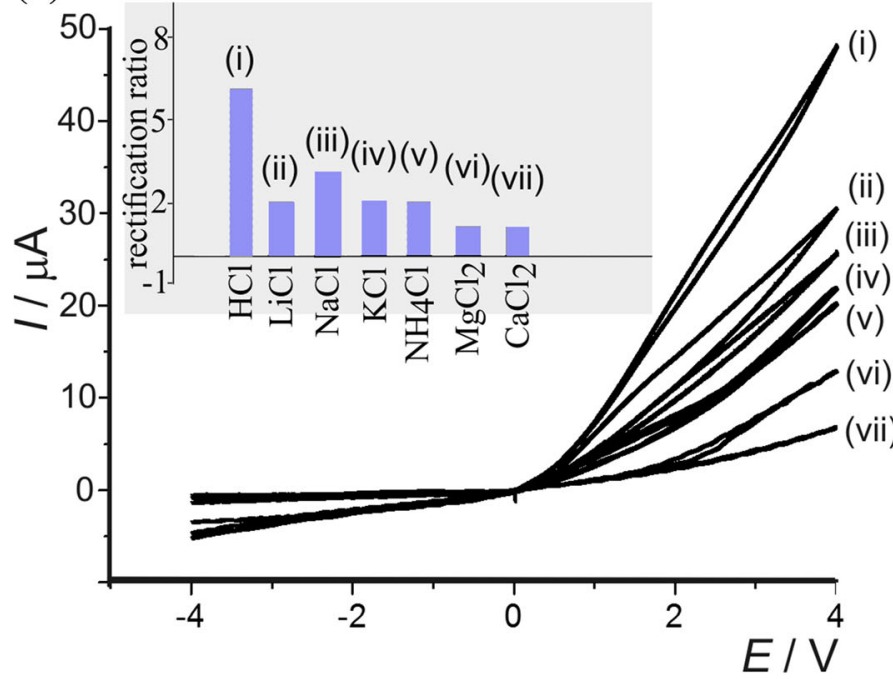

(b)

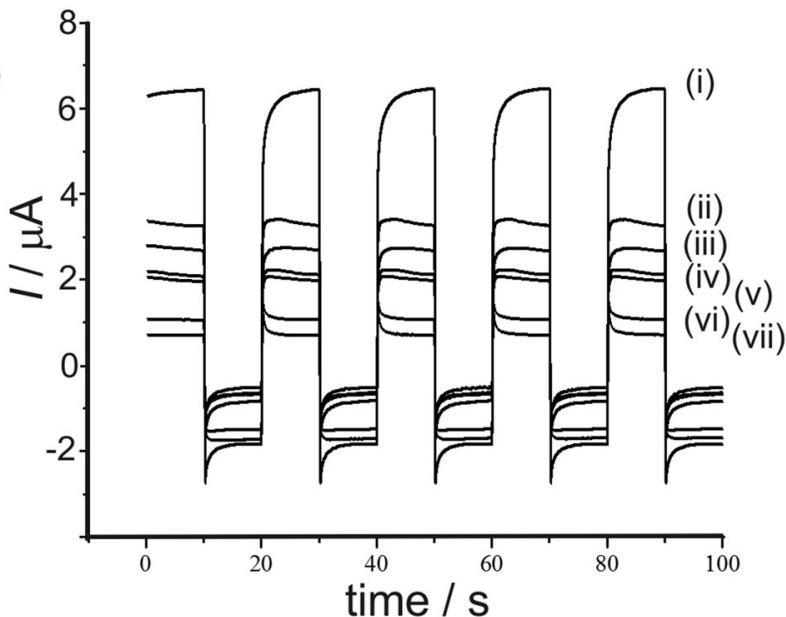

Fig. 5 Data for asymmetric titanate nanosheet deposits. a Cyclic voltammograms (scan rate $25 \mathrm{mV} \mathrm{s}^{-1}$ ), b chronoamperometry data (stepping from +1 to $-1 \mathrm{~V}$ ), immersed in aqueous (i) $\mathrm{HCl}$, (ii) $\mathrm{LiCl}$, (iii) $\mathrm{NaCl}$, (iv) $\mathrm{KCl}$, (v) $\mathrm{NH}_{4} \mathrm{Cl}$, (vi) $\mathrm{MgCl}_{2}$ and (vii) $\mathrm{CaCl}_{2}$ (10 $\mathrm{mM}$ on both sides). c Cyclic voltammograms (scan rate $25 \mathrm{mV} \mathrm{s}^{-1}$ ), d

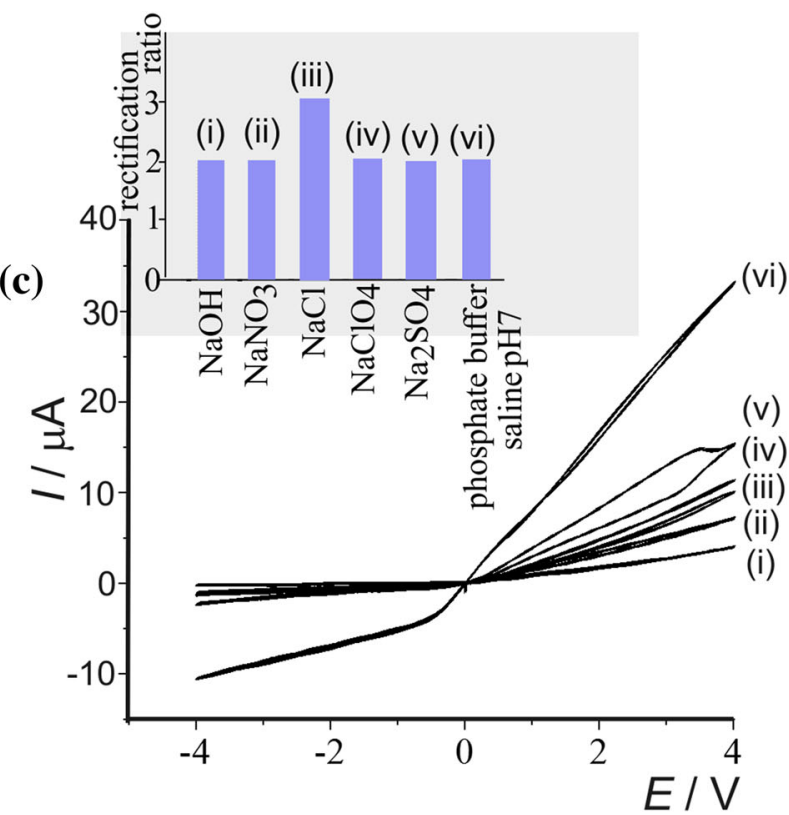

(d)

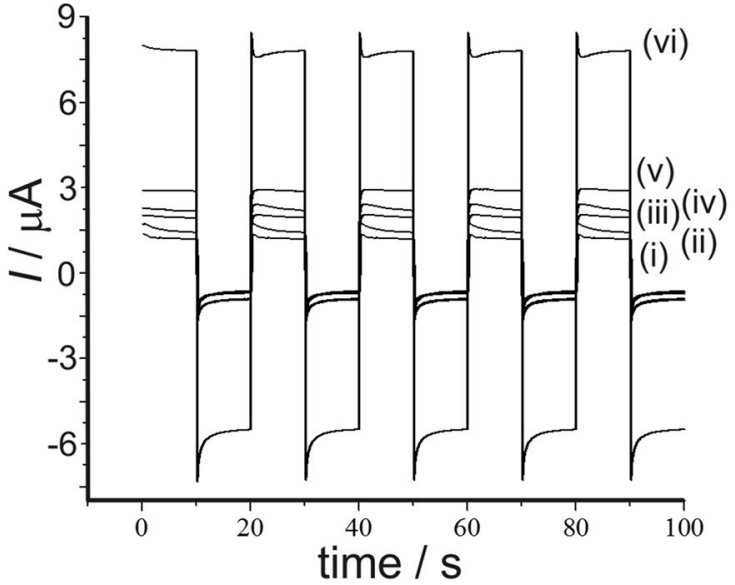

chronoamperometry data (stepping from +1 to $-1 \mathrm{~V}$ ), for films immersed in aqueous (i) $\mathrm{NaOH}$, (ii) $\mathrm{NaNO}_{3}$, (iii) $\mathrm{NaCl}$, (iv) $\mathrm{NaClO}_{4}$, (v) $\mathrm{Na}_{2} \mathrm{SO}_{4}$ and (vi) phosphate buffer saline $\mathrm{pH} 7$ (all $10 \mathrm{mM}$ on both sides). Insets show bar graphs for current rectification (see text) 
positive potential range) become significantly higher for higher valent anions $\left(\mathrm{SO}_{4}{ }^{2-}\right.$ and $\left.\mathrm{PO}_{4}{ }^{3-}\right)$, but effects of the type of anion on the rectification ratio data seem insignificant. Clearly, anions at a sufficiently high concentration can enter into the inter-lamellar space and significantly change the rate of transport. This suggests that there could be always an underlying contribution from anion transport, even when the cation transport appears dominant. Sulphate and phosphate are likely to more strongly collapse the internal double layer and thereby to open up the nanochannels to both cation and anion transport. This can give rise to a higher ion current and less semi-permeability. Chronoamperometry data show relatively complex transients (rising and falling) with transient features mainly taking place in the first $0.5 \mathrm{~s}$ of the data. It is likely that during this period, not only concentration gradients in the solution in the vicinity of the microhole develop, but also that concentration gradients within the nanosheet material change. The current traces measured during chronoamperometry may contain a component of 'adsorption currents' that are associated with compositional changes in the inter-lamellar space. Although electrolyte anion effects are clearly significant, it is currently difficult to disect these and to provide a more detailed assessment of the nature of these effects.

\section{Ion transport through lamellar titanate nanosheet deposits: competing cation and proton transport}

The observation of current through the titanate nanosheet deposit can be associated generally with three types of processes based on (i) flow of cations, (ii) flow of anions or (iii) the potentialdriven water heterolysis process leading to the formation of mobile protons and mobile hydroxide (with a resulting net $\mathrm{pH}$ gradient). The latter process has been reported for biological [52] and for bipolar membrane processes [53]. Catalysts for heterolytic water splitting such as graphene oxide [54] have been proposed to considerably enhance the potential-driven proton and hydroxide formation. In measurements as those reported in Fig. 5, it is not immediately clear whether water heterolysis can contribute to or even dominate the observed currents.

One way of directly monitoring the simultaneous formation of protons and hydroxide is by placing a secondary working electrode (WE2) into the two-compartment cell. Figure 6 shows a schematic drawing with WE2 place in the vicinity of the membrane and in the left counter electrode compartment. Initially, a cyclic voltammetry experiment was performed (with the three electrodes in the left compartment) to observe the onset potential for hydrogen evolution. In Fig. 6 a, data for $10 \mathrm{mM} \mathrm{HCl}$ are shown and the inset shows the onset at $-0.4 \mathrm{~V}$ vs. SCE (indicated by an arrow). Next, the fiveelectrode membrane cell is operated in cyclic voltammetry mode with the collector (WE2) potential fixed at the onset potential. Transport of protons associated with the open diode (at positive applied potentials) causes an increase in proton concentration at the location of WE2 and thereby leads to a current.

Figure 6 a shows both the generator current (WE1, membrane) and the collector current (WE2). The magnitude of the collector current approaches that of the generator current (with the opposite sign) in the case of a pure proton current. Therefore, the data for the proton transport for $10 \mathrm{mM} \mathrm{HCl}$ in Fig. 6 a provide proof for the methodology to work. Data in Fig. $6 \mathrm{~b}$ are shown for $10 \mathrm{mM} \mathrm{LiCl}$. Perhaps surprisingly, again a significant proton transport is observed with the collector current almost mirroring the generator current. This suggests that water heterolysis at titanate nanosheets is important and that the transport of $\mathrm{Li}^{+}$is likely to be accompanied by proton transport. Results for $\mathrm{NaCl}$ (Fig. 6c), $\mathrm{KCl}$ (Fig. 6d) and $\mathrm{NH}_{4} \mathrm{Cl}$ (Fig. 6e) are very similar, and also suggest proton formation by heterolysis and transport through the titanate film.

Data observed for $\mathrm{MgCl}_{2}$ (Fig. 6f) and for $\mathrm{CaCl}_{2}$ (Fig. 6g) are different not only with much lower proton fluxes, but also much lower generator currents. The shape of the voltammetric signal for $\mathrm{Ca}^{2+}$ is more complex and indicative of some blocking of the diode as the potential is scanned into the positive potential range. For both $\mathrm{Mg}^{2+}$ and $\mathrm{Ca}^{2+}$, small transient peaks are seen on the negative going potential scan, which could be associated with an 'unblocking' process. These observations are consistent with a blocking effect for $\mathrm{Mg}^{2+}$ and $\mathrm{Ca}^{2+}$ caused by a localised $\mathrm{pH}$ changes at the titanate film surface. Water heterolysis occurs at the titanate nanosheets, and this then causes locally the formation of hydroxide which then in combination with $\mathrm{Mg}^{2+}$ or $\mathrm{Ca}^{2+}$ causes blocking of the titanate nanochannels. However, the importance of this effect and the relative importance of proton versus electrolyte cation transport through the titanate film are difficult to quantify from these data. Further evidence for these processes comes from direct $\mathrm{pH}$ measurements.

In Fig. 7, a schematic drawing illustrates how two $\mathrm{pH}$ probes (glass membrane-based, battery controlled) are incorporated into the four-electrode electrochemical cell. The $\mathrm{pH}$ probes give a reading for the local $\mathrm{pH}$ (as an average) close to the PET film on the left and on the right. The photograph in Fig. 7 a shows the system before starting the experiment. With $10 \mathrm{mM} \mathrm{NaCl}$ in the left and right compartments, the $\mathrm{pH}$ is close to neutral. When operating the cationic diode at $+4 \mathrm{~V}$ (open), an average current of approximately $23 \mu \mathrm{A}$ flows and the $\mathrm{pH}$ value start to divert. After $10 \mathrm{~min}$ of operation (see Fig. $7 \mathrm{~b}$ ) the $\mathrm{pH}$ in the left compartment reaches 6.56 (more acidic) and in the right compartment 6.91 (less acidic). Figure $7 \mathrm{c}-\mathrm{d}$ summarise $\mathrm{pH}$ data for experiments in $1 \mathrm{mM}$ $\mathrm{NaCl}$ and in $10 \mathrm{mM} \mathrm{NaCl}$. For a concentration of $100 \mathrm{mM}$ $\mathrm{NaCl}, \mathrm{pH}$ changes were less significant. It is possible to relate these observations to the water heterolysis process.

The effect of protonic current flow through the diode can be estimated in terms of an upper limit for the $\mathrm{pH}$ changes in 

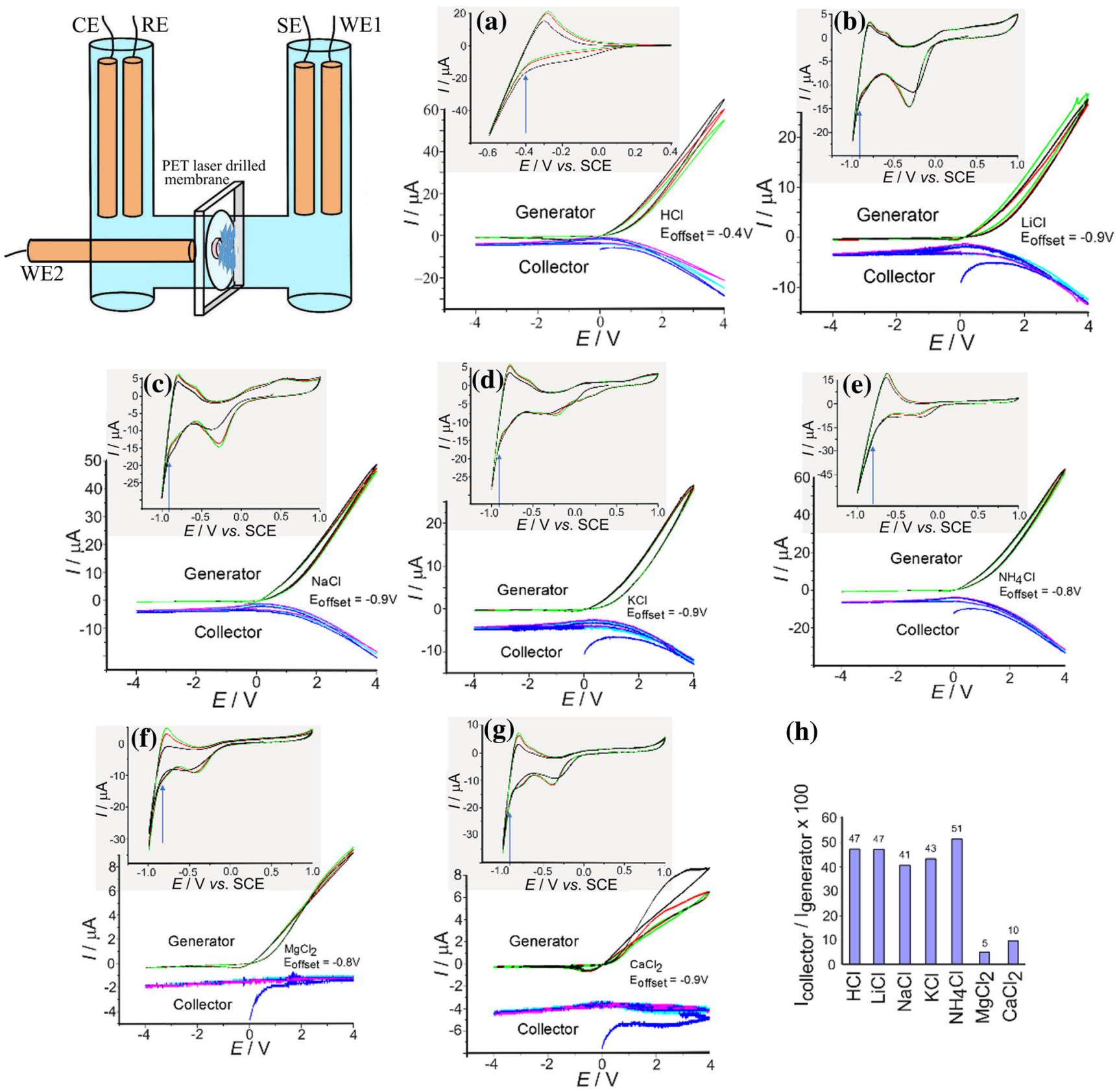

(h)

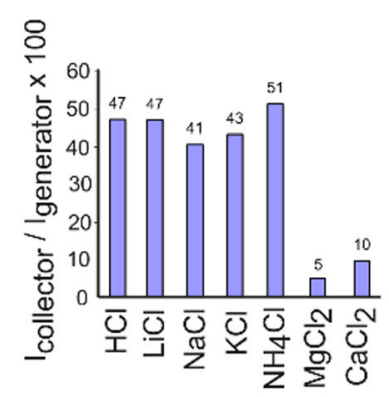

Fig. 6 Schematic drawing showing the five-electrode cell with additional (WE2, 3-mm diameter platinum disk) collector electrode for sensing proton flux. Data sets for a $10 \mathrm{mM} \mathrm{HCl}$, b $10 \mathrm{mM} \mathrm{LiCl}$, c $10 \mathrm{mM}$ $\mathrm{NaCl}$, d $10 \mathrm{mM} \mathrm{KCl}$, e $10 \mathrm{mM} \mathrm{NH}_{4} \mathrm{Cl}$, f $10 \mathrm{mM} \mathrm{MgCl}_{2}$ and g $10 \mathrm{mM}$ $\mathrm{CaCl}_{2}$ including the cyclic voltammogram (scan rate $50 \mathrm{mV} \mathrm{s}^{-1}$ ) at WE2

the right/left compartment when assuming a fixed volume $V$ of ca. $0.01 \mathrm{dm}^{3}$ (an estimated volume where $\mathrm{pH}$ changes occur close to the membrane surface). Eqs. (1) and (2) express the shift in $\mathrm{pH}$ (from the initial value $\mathrm{pH}_{\text {initial }}$ ) in the right compartment (where protons are lost) and in the left compartment (where protons are gained).

$\mathrm{pH}_{\text {left }}=-\log _{10}\left(10^{-\mathrm{pHinitial}}+I t / F V\right)$ showing onset of hydrogen evolution (blue arrow) and the generatorcollector voltammogram (three consecutive potential cycles, scan rate $50 \mathrm{mV} \mathrm{s}^{-1}$ ). h Bar graph comparing the ratio of collector current and generator current $($ at $+4 \mathrm{~V}$; in $\%$ ) for different electrolyte media

$\mathrm{pH}_{\text {right }}=14+\log _{10}\left(10^{-(14-\mathrm{pHinitial})}+I t / F V\right)$

Parameters in these equations are the time-average absolute current $I$, the time $t=600 \mathrm{~s}$ and the Faraday constant $F=$ 96,487 $\mathrm{C} \mathrm{mol}^{-1}$. For the case of a $1 \mathrm{mM} \mathrm{NaCl}$ electrolyte (see Fig. 7c), the average current at an applied voltage of $4 \mathrm{~V}$ was $10 \mu \mathrm{A}$ over $600 \mathrm{~s}$, which (with $\mathrm{pH}_{\text {initial }}=6.39$ ) translates to $\mathrm{pH}_{\text {left }}=5.2$ and $\mathrm{pH}_{\text {right }}=8.8$. Comparison to the experimental results in Fig. $7 \mathrm{c}$ shows that the predicted trend is indeed 

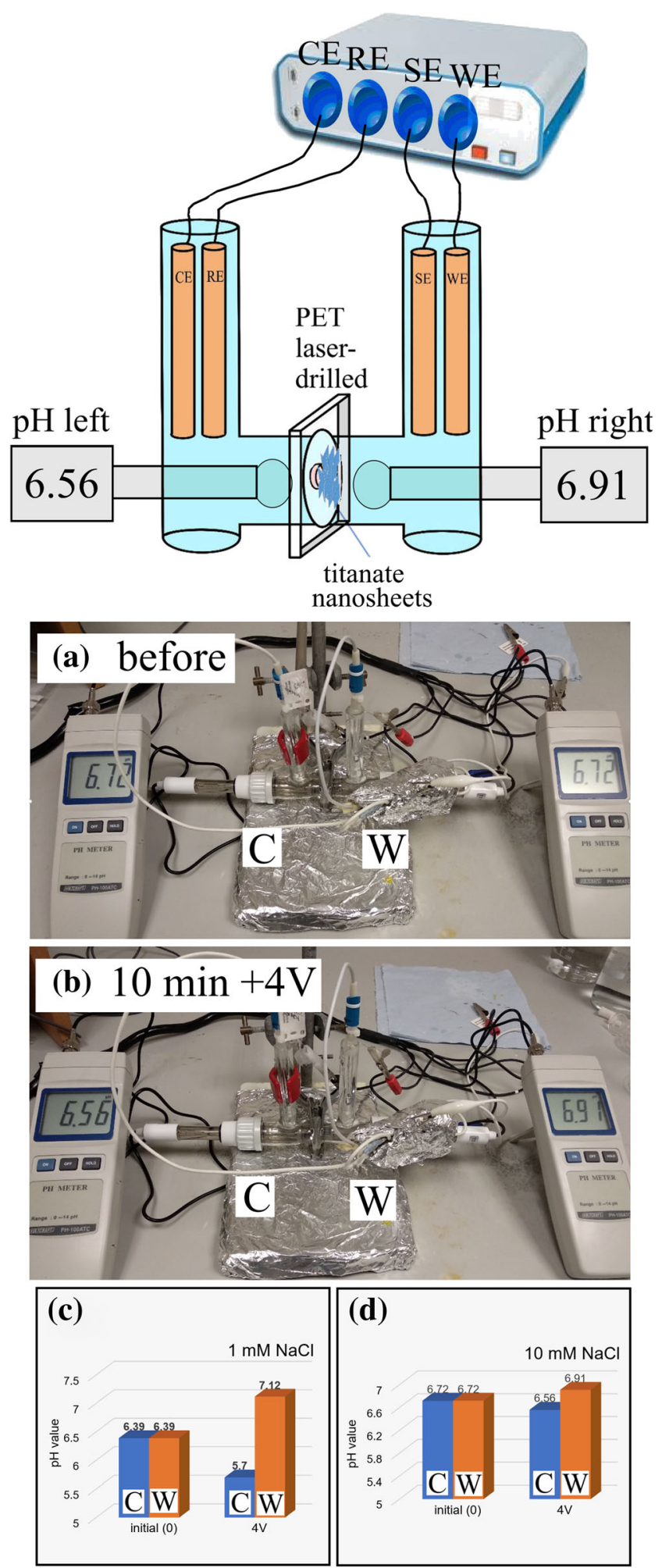

Fig. 7 Illustration of the experimental system. a Photograph showing the experimental cell with the left compartment (counter electrode and reference electrode) and the right compartment (working electrode and sense electrode). In both compartments, an additional battery-driven $\mathrm{pH}$ sensor is added to probe the $\mathrm{pH}$ close to the PET film in the middle. $\mathbf{b}$ After $10 \mathrm{~min}+4 \mathrm{~V}$ and $23 \mu \mathrm{A}$ current the $\mathrm{pH}$ has become more acidic on the left and more alkaline on the right. Bar graphs for the effect at $10 \mathrm{~min}$ $+4 \mathrm{~V}$ for $\mathbf{c} 1 \mathrm{mM} \mathrm{NaCl}(10 \mu \mathrm{A})$ and $\mathbf{d} 10 \mathrm{mM} \mathrm{NaCl}(23 \mu \mathrm{A})$ observed. For a concentration of $10 \mathrm{mM} \mathrm{NaCl}$ (Fig. 7d), the observed average current was $23 \mu \mathrm{A}$ at $4 \mathrm{~V}$ applied voltage. This gives $\mathrm{pH}_{\mathrm{left}}=4.8$ and $\mathrm{pH}_{\text {right }}=9.2$. Experimental data suggest a less strong change in $\mathrm{pH}$ and therefore less competition between $\mathrm{Na}^{+}$transport and water heterolysis at the higher $\mathrm{NaCl}$ concentration. Additional experiments for $100 \mathrm{mM} \mathrm{NaCl}$ (not shown) suggest even lower $\mathrm{pH}$ drift even at higher currents. Water heterolysis appears to be strongly electrolyte concentration dependent and probably insignificant at electrolyte concentrations of $10 \mathrm{mM}$ or higher. Although conclusive in terms of providing direct evidence for the water heterolysis process, the data provide only qualitative insights and further work will be required to provide a quantitative measure of the water heterolysis process under these conditions.

\section{Ion transport through lamellar titanate nanosheet deposits: interference of $\mathrm{NBu}_{4}{ }^{+}$with proton transport}

The presence of $\mathrm{NBu}_{4}{ }^{+}$cation in the original titanate host material is due to the exfoliation process requiring a bulky tetraalkylammonium reagent. When depositing titanate nanosheets onto the PET film, $\mathrm{NBu}_{4}{ }^{+}$cations are present and they define the ability of the titanate lamellae to bind to host molecules [24] and to conduct ions. It is therefore important to also investigate the effect of $\mathrm{NBu}_{4}{ }^{+}$cations on the ionic current rectification and on the ion conductivity. Figure 8 a shows membrane voltammetry data for $10 \mathrm{mM} \mathrm{HCl}$ electrolyte initially in both sides of the two-compartment cell. The typical cationic diode response is observed (Fig. 8a(i)). When adding $\mathrm{NBu}_{4} \mathrm{Cl}$ into the right compartment, this can equilibrate with the titanate nanosheet deposit and change the ability of the lamellar structure to conduct ions. Data in Fig. 8 a demonstrate a systematic decrease in ion current (and in rectification ratio) as the concentration of $\mathrm{NBu}_{4} \mathrm{Cl}$ increases. Ultimately, when adding $50 \mathrm{mM} \mathrm{NBu}_{4} \mathrm{Cl}$, the ionic diode is inverted. The switch of the open diode state from positive potential to negative potential is a strong indication for a change from a cationic diode to an anionic diode. This is also confirmed in chronoamperometry data in Fig. 8 b. The current transient shows a rising current when opening the diode. In the presence of $50 \mathrm{mM} \mathrm{NBu}_{4} \mathrm{Cl}$, the behaviour switches and the rising current transient is observed in the negative potential domain.

It is possible to envisage the processes responsible for the ion transport in the lamellar structure based on the equilibration of competing cation in the titanate double layer. Both protons and $\mathrm{NBu}_{4}{ }^{+}$can be bound (Fig. 8c). In the absence of $\mathrm{NBu}_{4}{ }^{+}$ vacancies exist for protons (or other cations) to bind and to conduct through the titanate deposit. However, when adding $\mathrm{NBu}_{4}{ }^{+}$cations these bind and block the transport of other cations (protons). For $10 \mathrm{mM} \mathrm{NBu}_{4}{ }^{+}$cations both the current in the open state and the rectification ratio half. When adding more $\mathrm{NBu}_{4} \mathrm{Cl}$, it is possible to 'invert' the diode behaviour. This can be explained by excess of $\mathrm{NBu}_{4} \mathrm{Cl}$ binding 


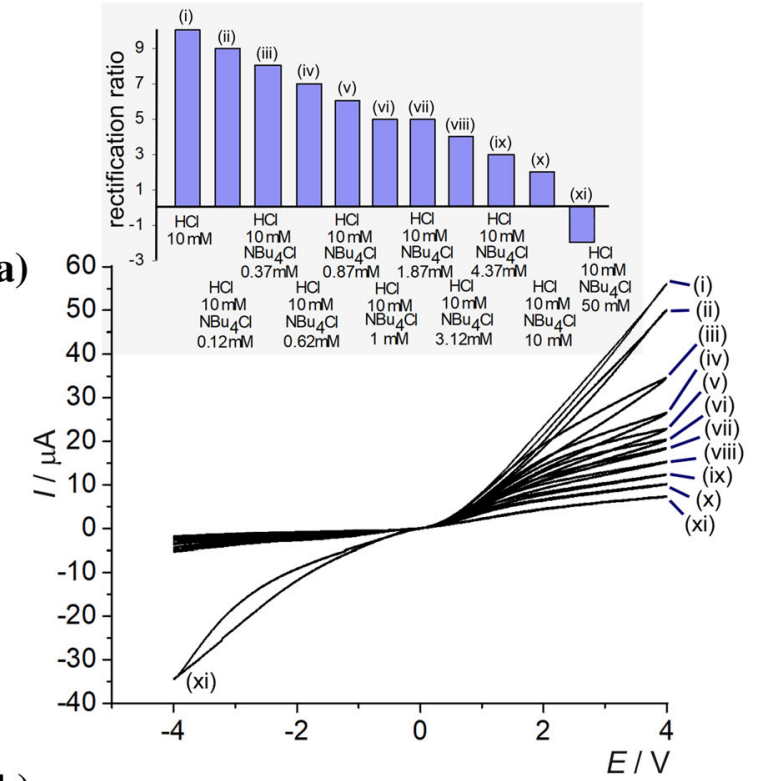

(b)
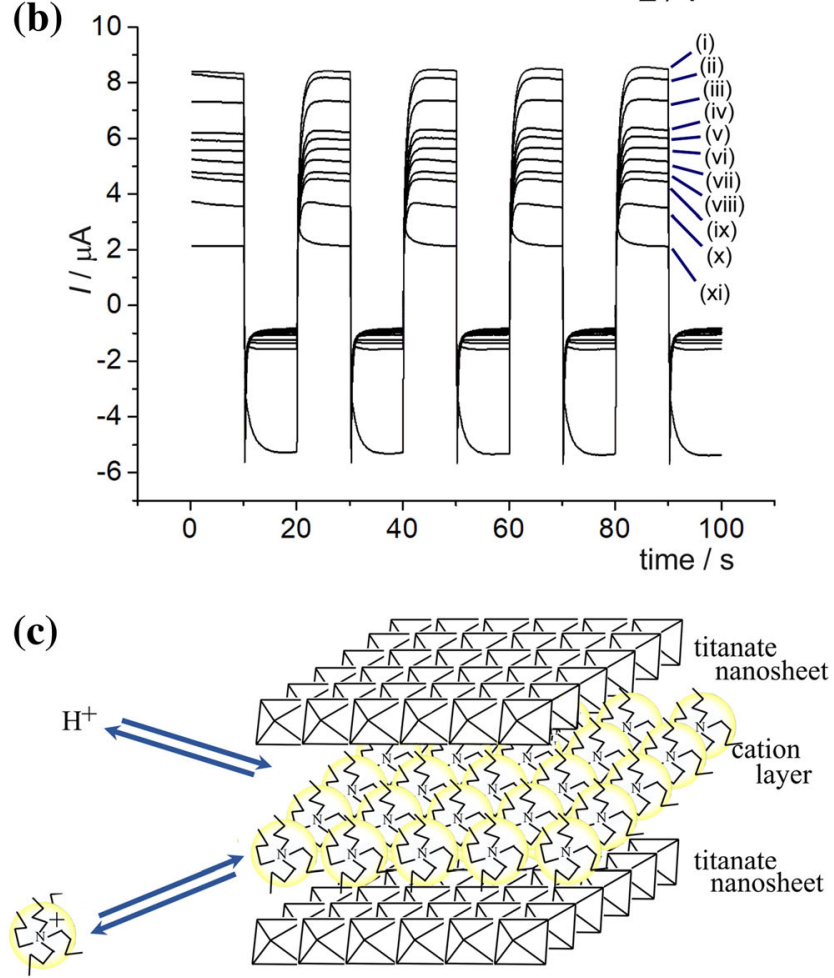

Fig. 8 a Asymmetric $\mathrm{TiO}_{2}$ nanosheet data for cyclic voltammograms (scan rate $25 \mathrm{mV} \mathrm{s}^{-1}$ ) in aqueous electrolyte (for $10 \mathrm{mM} \mathrm{HCl}$ on the left and (i) $10 \mathrm{mM} \mathrm{HCl}$, (ii) $10 \mathrm{mM} \mathrm{HCl}+0.12 \mathrm{mM} \mathrm{NBu}_{4} \mathrm{Cl}$, (iii) $10 \mathrm{mM} \mathrm{HCl}+0.37 \mathrm{mM} \mathrm{NBu}_{4} \mathrm{Cl}$, (iv) $10 \mathrm{mM} \mathrm{HCl}+0.62 \mathrm{mM} \mathrm{NBu}_{4} \mathrm{Cl}$, (v) $10 \mathrm{mM} \mathrm{HCl}+0.87 \mathrm{mM} \mathrm{NBu}_{4} \mathrm{Cl}$, (vi) $10 \mathrm{mM} \mathrm{HCl}+1 \mathrm{mM} \mathrm{NBu}_{4} \mathrm{Cl}$, (vii) $10 \mathrm{mM} \mathrm{HCl}+1.87 \mathrm{mM} \mathrm{NBu}_{4} \mathrm{Cl}$, (viii) $10 \mathrm{mM} \mathrm{HCl}+3.12 \mathrm{mM}$ $\mathrm{NBu}_{4} \mathrm{Cl}$, (ix) $10 \mathrm{mM} \mathrm{HCl}+4.37 \mathrm{mM} \mathrm{NBu}_{4} \mathrm{Cl}$, (x) $10 \mathrm{mM} \mathrm{HCl}+$ $10 \mathrm{mM} \mathrm{NBu}{ }_{4} \mathrm{Cl}$, (xi) $10 \mathrm{mM} \mathrm{HCl}+50 \mathrm{mM} \mathrm{NBu}_{4} \mathrm{Cl}$, on the right). $\mathbf{b}$ Chronoamperometry data (stepping from +1 to $-1 \mathrm{~V}$ ) immersed in aqueous electrolyte. Inset: rectification ratio calculation from chronoamperometry data at $\pm 1 \mathrm{~V}$. c Schematic description of the competition of protons and tetrabutylammonium cations

into the inter-lamellar space and a net anion transport mechanism (due to mobile chloride) being activated.
More work will be needed to further exploit this switch from cationic to anionic current rectification.

\section{Summary and conclusions}

It has been shown that asymmetry in the deposition of a titanate nanosheet film can be used to induce current rectification phenomena or ionic diode effects, as long as the semipermeable character due to cation transport is maintained. In this case, a 'cationic diode' has been produced with rectification effects observed for many types of cations. A cation vacancy model is proposed based on $\mathrm{NBu}_{4}{ }^{+}$cations occupying part of the inter-lamellar space with vacancies for other types of cations to bind. The excess of negative charges on the titanate allow cation binding and transport.

The rectification ratio for $\mathrm{NaCl}$ electrolyte considerably decreased when concentration of aqueous $\mathrm{NaCl}$ (or the ionic strength) was increased on the side of titanate nanosheet film (consistent with anion uptake into the lamellar space and anion transport in addition to cation transport at higher ionic strength). Currents for the open diode are shown to be associated with additional water hydrolysis and proton transport rather than pure $\mathrm{Li}^{+}, \mathrm{Na}^{+}, \mathrm{K}^{+}, \mathrm{NH}_{4}^{+}, \mathrm{Mg}^{2+}$ and $\mathrm{Ca}^{2+}$ transport. In the case of $\mathrm{Mg}^{2+}$ and $\mathrm{Ca}^{2+}$, this resulted in blocking of transport presumably due to precipitation effects in the presence of hydroxide. Water heterolysis requires catalytic sites for the potential-driven dissociation reaction. Sharp edges at the 2D-titanate surfaces (causing high local field gradients) with a $\mathrm{pK}_{\mathrm{A}}$ close to 4 (resulting in active sites for field-driven water dissociation) could provide well-suited reaction environments, but further study will be needed to confirm this. A more quantitative observation of the relative contributions of proton and electrolyte cation transport to the diode current will be required. $\mathrm{NBu}_{4}{ }^{+}$cations have been shown to suppress cation conduction and ultimately 'invert' the diode to anion conduction due to an increase in positive charge in the lamellar space. In order to improve the understanding of these processes, in future, theory could be developed at both the atomic level and the meso-level to take in account localised field effects as well as interfacial concentration gradient/polarisation effects that are caused by the current flow.

Applications of titanate films could be possible (i) under low ionic strength conditions as a catalyst for water heterolysis [55] or (ii) under higher ionic strength conditions in desalination. However, the ability of the lamellar structures to maintain effective rectification at higher ionic strengths is currently poor. Therefore, the inter-lamellar space needs to be better designed to maintain a higher rectification effect (by maintaining semi-permeability). This could be achieved by tuning the concentration and structure of the tetraalkylammonium guest cations. Further work will be directed toward the effects of inter-lamellar guests on the mechanism and the use of nanosheet materials in desalination and sensing. 
Acknowledgements B.R.P. would like to thank the Indonesian Endowment (LPDP RI) for a PhD scholarship.

Open Access This article is distributed under the terms of the Creative Commons Attribution 4.0 International License (http:// creativecommons.org/licenses/by/4.0/), which permits unrestricted use, distribution, and reproduction in any medium, provided you give appropriate credit to the original author(s) and the source, provide a link to the Creative Commons license, and indicate if changes were made.

Publisher's note Springer Nature remains neutral with regard to jurisdictional claims in published maps and institutional affiliations.

\section{References}

1. Kumar P, Bansal V, Kim KH, Kwon EE (2018) Metal-organic frameworks (MOFs) as futuristic options for wastewater treatment. J Industrial Engineer Chem 62:130-145

2. Xu D, Guo JN, Yan F (2018) Porous ionic polymers: Design, synthesis, and applications. Progress Polymer Sci 79:121-143

3. Sajjad S, Leghari SAK, Iqbal A (2017) Study of graphene oxide structural features for catalytic, antibacterial, gas sensing, and metals decontamination environmental applications. ACS Appl Mater Interfaces 9:43393-43414

4. Zhu XY, Yang KJ, Chen BL (2017) Membranes prepared from graphene-based nanomaterials for sustainable applications: a review. Environm Sci Nano 4:2267-2285

5. Sorrentino A, Tortora M, Vittoria V (2006) Diffusion behavior in polymer-clay nanocomposites. J Polymer Sci B Polymer Phys 44: 265-274

6. Fathizadeh M, Xu WWL, Zhou FL, Yoon Y, Yu M (2017) Graphene oxide: A novel 2-dimensional material in membrane separation for water purification. Adv Mater Interfaces 4:1600918

7. Sun P, Ma R, Sasaki T (2018) Recent progress on exploring exceptionally high and anisotropic $\mathrm{H}+/ \mathrm{OH}$ - ion conduction in two-dimensional materials. Chem Sci 9:33-43

8. Huang HB, Ying YL, Peng XS (2014) Graphene oxide nanosheet: an emerging star material for novel separation membranes. J Mater Chem A 2:13772-13782

9. Hirsch A, Hauke F (2018) Post-graphene 2D chemistry: The emerging field of molybdenum disulfide and black phosphorus functionalization. Angew Chem Inter Ed 57:4338-4354

10. ten Elshof JE, Yuan HY, Rodriguez PG (2016) Two-dimensional metal oxide and metal hydroxide nanosheets: Synthesis, controlled assembly and applications in energy conversion and storage. Adv Energy Mater 6:1600355

11. Tan CL, Zhang H (2015) Two-dimensional transition metal dichalcogenide nanosheet-based composites. Chem Soc Rev 44: 2713-2731

12. Xu J, Bian ZY, Xin X, Chen AC, Wang H (2018) Size dependence of nanosheet BiVO4 with oxygen vacancies and exposed $\{001\}$ facets on the photodegradation of oxytetracycline. Chem Engineer J 337:684-696

13. Ding L, Wei YY, Wang YJ, Chen HB, Caro J, Wang HH (2017) A two-dimensional lamellar membrane: MXene nanosheet stacks. Angew Chem Inter Ed 56:1825-1829

14. Matsumoto Y, Funatsu A, Matsuo D, Ozawa K (2001) Electrochemistry of titanate(IV) layered oxides. J Phys Chem B 105:10893-10899

15. Sasaki T (1998) Molecular nanosheets of quasi-TiO2: preparation and spontaneous reassembling. Supramolecular Sci 5:367-371
16. Chen XB, Mao SS (2007) Titanium dioxide nanomaterials: Synthesis, properties, modifications, and applications. Chem Rev 107:2891-2959

17. Sasaki T, Watanabe M (1998) Osmotic swelling to exfoliation. Exceptionally high degrees of hydration of a layered titanate. J Am Chem Soc 120:4682-4689

18. Maluangnont T, Matsuba K, Geng FX, Ma RZ, Yamauchi Y, Sasaki $\mathrm{T}$ (2013) Osmotic swelling of layered compounds as a route to producing high-quality two-dimensional materials. A comparative study of tetramethylammonium versus tetrabutylammonium cation in a Lepidocrocite-type titanate. Chem Mater 25:3137-3146

19. Yuan H, Besselink R, Liao ZL, ten Elshof JE (2014) The swelling transition of Lepidocrocite-type protonated layered titanates into anatase under hydrothermal treatment. Sci Rep 4:4584-4589

20. Wahyuni WT, Putra BR, Harito C, Bavykin DV, Walsh FC, James TD, Kociok-Kohn G, Marken F (2018) Electroanalysis in 2D-TiO2 nanosheet hosts: Electrolyte and selectivity effects in ferroceneboronic acid - saccharide binding. Electroanalysis 30: $1303-1310$

21. Sasaki T, Ebina Y, Kitami Y, Watanabe M, Oikawa T (2001) Twodimensional diffraction of molecular nanosheet crystallites of titanium oxide. J Phys Chem B 105:6116-6121

22. Patil SB, Kim HJ, Lim HK, Oh SM, Kim J, Shin J, Kim H, Choi JW, Hwang SJ (2018) Exfoliated 2D Lepidocrocite titanium oxide nanosheets for high sulfur content cathodes with highly stable Li-S battery performance. ACS Energy Lett 3:412-419

23. Lee Y, Kwon KY (2017) Synthesis and oxidative catalytic property of ruthenium-doped titanate nanosheets. Appl Chem Engineer 28: 593-596

24. Lu DZ, Fang PF, Ding JQ, Yang MC, Cao YF, Zhou YW, Peng K, Kondamareddy KK, Liu M (2017) Two-dimensional TiO2-based nanosheets co-modified by surface-enriched carbon dots and $\mathrm{Gd} 2 \mathrm{O} 3$ nanoparticles for efficient visible-light-driven photocatalysis. Appl Surf Sci 396:185-201

25. Harito C, Bavykin DV, Walsh FC (2017) Incorporation of titanate nanosheets to enhance mechanical properties of water-soluble polyamic acid. In: Yudianti R, Azuma J (eds) Innovation in Polymer Science and Technology. IOP Conference SeriesMaterials Science and Engineering, vol 223, p 012054. https://doi. org/10.1088/1757-899X/223/1/012054

26. Wahyuni WT, Putra BR, Harito C, Bavykin DV, Walsh FC, Fletcher PJ, Marken F (2019) Extraction of hydrophobic analytes from organic solution into a titanate 2D-nanosheet host: Electroanalytical perspectives. Anal Chim Acta X. https://oi.org/10.1016/j.acax. 2018.100001

27. Lam HT, Pereira CM, Roussel C, Carrupt PA, Girault HH (2006) Immobilized $\mathrm{pH}$ gradient gel cell to study the $\mathrm{pH}$ dependence of drug lipophilicity. Anal Chem 78:1503-1508

28. Aaronson BDB, He DP, Madrid E, Johns MA, Scott JL, Fan L, Doughty J, Kadowaki MAS, Polikarpov I, McKeown NB, Marken F (2017) Ionic diodes based on regenerated alpha-cellulose films deposited asymmetrically onto a microhole. Chem Select 2: 871-875

29. He DP, Madrid E, Aaronson BDB, Fan L, Doughty J, Mathwig K, Bond AM, McKeown NB, Marken F (2017) A cationic diode based on asymmetric Nafion film deposits. ACS Appl Mater Interfaces 9: $11272-11278$

30. Tshwenya L, Arotiba O, Putra BR, Madrid E, Mathwig K, Marken F (2018) Cationic diodes by hot-pressing of Fumasep FKS-30 ionomer film onto a microhole in polyethylene terephthalate (PET). J Electroanal Chem 815:114-122

31. Putra BR, Aoki KJ, Chen JY, Marken F (2019) A cationic rectifier based on a graphene oxide covered microhole: Theory and experiment. Langmuir. https://doi.org/10.1021/acs.langmuir.8b03223

32. Rong YY, Song QL, Mathwig K, Madrid E, He DP, Niemann RG, Cameron PJ, Dale SEC, Bending S, Carta M, McKeown NB, 
Marken F (2016) pH-induced reversal of ionic diode polarity in 300 $\mathrm{nm}$ thin membranes based on a polymer of intrinsic microporosity. Electrochem Commun 69:41-45

33. Madrid E, Cottis P, Rong YY, Rogers AT, Stone JM, MalpassEvans R, Carta M, McKeown NB, Marken F (2015) Water desalination concept using an ionic rectifier based on a polymer of intrinsic microporosity (PIM). J Mater Chem A 3:15849-15853

34. Putra BR, Carta M, Malpass-Evans R, McKeown NB, Marken F (2017) Potassium cation induced ionic diode blocking for a polymer of intrinsic microporosity | Nafion "heterojunction" on a microhole substrate. Electrochim Acta 258:807-813

35. Mathwig K, Aaronson BDB, Marken F (2018) Ionic transport in microhole fluidic diodes based on asymmetric ionomer film deposits. ChemElectroChem 5:897-901

36. Madrid E, Rong YY, Carta M, McKeown NB, Malpass-Evans R, Attard GA, Clarke TJ, Taylor SH, Long YT, Marken F (2014) Metastable ionic diodes derived from an amine-based polymer of intrinsic microporosity. Angew Chem Inter Ed 53(40):1075110754

37. Guo W, Tian Y, Jiang L (2013) Asymmetric ion transport through ion-channel-mimetic solid-state nanopores. Acc Chem Res 46: 2834-2846

38. Lan WJ, Edwards MA, Luo L, Perera RT, Wu XJ, Martin CR, White HS (2016) Voltage-rectified current and fluid flow in conical nanopores. Acc Chem Res 49:2605-2613

39. Zhang Z, Wen LP, Jiang L (2018) Bioinspired smart asymmetric nanochannel membranes. Chem Soc Rev 47:322-356

40. Cheng LJ, Guo LJ (2010) Nanofluidic diodes. Chem Soc Rev 39: 923-938

41. Lovrecek B, Despic A, Bockris JOM (1959) Electrolytic junctions with rectifying properties. J Phys Chem 63:750-751

42. Hegedus L, Kirschner N, Wittmann M, Noszticzius Z (1998) Electrolyte transistors: Ionic reaction-diffusion systems with amplifying properties. J Phys Chem A 102:6491-6497

43. Boon N, de la Cruz MO (2015) 'Soft' amplifier circuits based on field-effect ionic transistors. Soft Matter 11:4793-4798

44. Zhao R, He GH, Deng YL (2012) Non-water ionic diode based on bias-dependent precipitation. Electrochem Commun 23:106-109
45. Madrid E, Buckingham MA, Stone JM, Rogers AT, Gee WJ, Burrows AD, Raithby PR, Celorrio V, Fermin DJ, Marken F (2016) Ion flow in a zeolitic imidazolate framework results in ionic diode phenomena. Chem Commun 52:2792-2794

46. Chun H, Chung TD (2015) Iontronics. Ann Rev Anal Chem 8:441462

47. Kautz R, Ordinario DD, Tyagi V, Patel P, Nguyen TN, Gorodetsky AA (2018) Cephalopod-derived biopolymers for ionic and protonic transistors. Adv Mater 30:1704917

48. Jana SK, Banerjee S, Bayan S, Inta HR, Mahalingam V (2018) Rectification and amplification of ionic current in planar graphene/graphene-oxide junctions: An electrochemical diode and transistor. J Phys Chem C 122:11378-11384

49. Harito C, Bavykin DV, Light ME, Walsh FC (2017) Titanate nanotubes and nanosheets as a mechanical reinforcement of water-soluble polyamic acid: Experimental and theoretical studies. Composites B 124:54-63

50. Martins AS, Harito C, Bavykin DV, Walsh FC, Lanza MRV (2017) Insertion of nanostructured titanates into the pores of an anodised $\mathrm{TiO} 2$ nanotube array by mechanically stimulated electrophoretic deposition. J Mater Chem C 5:3955-3961

51. Brown R, Madrid E, Castaing R, Stone JM, Squires AM, Edler KJ, Takashina K, Marken F (2017) Free-standing phytantriol Q(224) cubic-phase films: Resistivity monitoring and switching. ChemElectroChem 4:1172-1180

52. Simons R (1985) Water splitting in ion-exchange membranes. Electrochim Acta 30:275-282

53. Strathmann H, Krol JJ, Rapp HJ, Eigenberger G (1997) Limiting current density and water dissociation in bipolar membranes. J Mem Sci 125:123-142

54. McDonald MB, Freund MS (2014) Graphene oxide as a water dissociation catalyst in the bipolar membrane interfacial layer. ACS Appl Mater Interfaces 6:13790-13797

55. Yan ZF, Zhu L, Li YGC, Wycisk RJ, Pintauro PN, Hickner MA, Mallouk TE (2018) The balance of electric field and interfacial catalysis in promoting water dissociation in bipolar membranes. Energy Environm Sci 11:2235-2245 